\title{
Wine and music (III): so what if music influences the taste of the wine?
}

\author{
Charles Spence ${ }^{*}$ and Qian Janice Wang
}

\begin{abstract}
A growing body of evidence, both anecdotal and scientifically rigorous, now points to the fact that what people taste when evaluating a wine, not to mention how much they enjoy the experience, can be influenced by the specifics of any music that happens to be playing at the same time. The question that we wish to address here is 'So what?' Why should anyone care that music (or, for that matter, specially composed soundscapes) exert(s) a crossmodal influence over the wine-tasting experience? 'Why not just drink great wine and forget about the music?' a sceptic might ask. Here, we outline a number of the uses that such research findings have been put to in the marketplace, in experiential events, in artistic performances, and in terms of furthering our theoretical understanding of those factors that influence the tasting experience. We also highlight how the latest in technology (think sensory apps and hyperdirectional loudspeakers, not to mention digitally augmented glassware) augurs well for those wanting to deliver the most stimulating, the most memorable, and certainly the most multisensory of tasting experiences in the years to come. Demonstrations of sound's influence on wine perception will most likely be applicable to a variety of other drinks and foods too. Ultimately, the argument is forwarded that there are many reasons, both theoretical and applied, as to why we should all care about the fact that what we listen to can change the sensory-discriminative, the descriptive, and the hedonic attributes of what we taste.
\end{abstract}

Keywords: Wine, Music, Multisensory experience design, Soundscapes, Emotion, Crossmodal correspondences

\section{Review}

For over half a century now, scientists have been interested in the question of whether what we hear influences what we taste (see $[1,2]$ for early work; and $[3,4]$ for recent reviews). A large body of evidence shows that the sounds made by many foods as we eat them can influence the tasting experience (see [5], for a review). However, what has really captured the public's imagination in recent years (e.g. [6-8]) is the suggestion that the background music and soundscapes that often accompany our everyday drinking experiences (and which would seem to be totally unrelated to the taste of the wine itself) can nevertheless still exert a significant influence over the hedonic, the sensory, and the descriptive attributes of wine. What is also startling, at least to some, is that such crossmodal effects appear to affect both wine experts and social drinkers alike $[9,10]$. While some commentators have,

\footnotetext{
* Correspondence: charles.spence@psy.ox.ac.uk

Crossmodal Research Laboratory, Department of Experimental Psychology,

Oxford University, South Parks Road, Oxford OX1 3UD, UK
}

naturally enough, been sceptical about such claims (see $[10,11])$, we would argue that the weight of the empirical evidence (collected from rigorously controlled scientific experiments conducted over the last couple of years, backed up by extensive anecdotal reports from many quarters; e.g. $[9,12]$ now firmly supports the conclusion that what we listen to when we taste wine affects what we think about what we taste (see [13] for a review).

However, one concern that is sometimes raised here is whether the sole reason for wanting to use music to complement the wine drinking experience is to cover up the flaws in a mediocre wine. Melanie Reid, writing in The Times, captured the sentiment when she said 'Do not be surprised if restaurants start playing Wagner to disguise the taste of the house red. Scientists have discovered that music influences taste - and that listening to powerful, heavy music makes wine seem richer and heavier.' [8]. So, what, exactly, can one hope to achieve by choosing the right music when drinking wine? Well, just take the following quote from James John, Director of the Bath Wine School, concerning the combination of 
Mozart's Laudate Dominum with Chardonnay as a suggestion as to what can happen under the appropriate multisensory conditions: '[...] Just as the sonant complexity is doubled, the gustatory effects of ripe fruit on toasted vanilla explode on the palate and the appreciation of both is taken to an entirely new level' (quoted in [14]). Indeed, as we will see later, the research now suggests that any wine (i.e. regardless of the price point or quality) can be influenced to a greater or lesser extent by music. Whether we need to attend to the music, though, in order to see such effects, is another matter entirely. ${ }^{1}$

\section{Modifying the tasting experience with music}

When thinking about music's influence on the tasting experience, it can be helpful to discriminate between four different kinds of judgments, or impressions, that we may ascribe to a wine: Hedonic-how much do we like the wine? Sensory-our assessment of the physical properties of the wine (e.g. sweetness, acidity, alcohol) and their impact on the drinker (astringency, length, etc.); Analytic-concerning such attributes as age, complexity, balance, quality, and price assessment; and Descriptive-would we describe the wine as heavy or light, zingy or lush, masculine or feminine?

\section{Music's influence on the hedonic rating of wine}

That wine can be made 'more delicious', in Californian winemaker, Clark Smith's words (quoted in [15]) by pairing it with the right music is surely no bad thing. However, while one might well be happy to acknowledge that music can help to give a mediocre wine something of a lift, one can imagine many people wanting to resist any suggestion that music could do anything to enhance the experience associated with tasting a great wine. However, evidence against such a suggestion comes from a series of experiments reported by Spence et al. [16]. These researchers measured the impact of matching music on people's ( $N=26$ participants) ratings of how much they liked three high-end wines (retailing at between roughly $£ 150-400$ a bottle), when compared to tasting in silence. The results revealed a small (c. $5 \%$ ), but nevertheless still significant, enhancement of their participants' liking of the wine, even for such high-end offerings. Thus, it would seem that music can enhance our liking for wine, regardless of the price point. Perhaps, though, we might nevertheless still expect to see a larger enhancement effect for mediocre wine as a result of playing the right music.

One of the striking findings to have emerged from a number of the previous studies in this area is that the better a drinker thinks that the music matches the wine, the more they appear to enjoy the tasting experience ([17, 18]; cf [19]). The existence of such a correlation can perhaps be explained in terms of the notion of "processing fluency' $[20,21]$. That is, when the music and wine are congruent, people may find it easier to evaluate/process the sensory properties of both (that is, the processing fluency is higher). Hence, people may find their tasting experience a little more pleasant as a result (cf. [22]). Of course, by the same token, drinking wine while listening to incongruent, or mismatching, music should lead to reduced ratings of pleasantness, as the combination will likely be somewhat more difficult to process. Here, one might hazard a guess that more damage can be done to a taster's experience of a very expensive (or should that be good; see [23]) wine by pairing it with the wrong music than by playing mismatching music with a cheap wine.

It is perhaps also worth noting that people (social drinkers) have been shown to prefer wines while listening to certain pieces of music rather than others [18]. While such generalized effects might again be accounted for in terms of processing fluency-i.e. some music is simply easier to process than other music regardless of what it is paired with, it might also be explained in terms of the notion of 'sensation transference'. According to the latter notion, taken from the field of marketing research, the suggestion is that our judgments of what we think about one stimulus, let us call it the wine, can be influenced by a seemingly unrelated stimulus (let us call it the music), because we have a tendency to transfer our thoughts and feelings about the music (i.e. our hedonic liking of it) to our rating of the wine [24].

\section{Music's influence on the descriptive aspects of tasting}

Over-and-above any influence that music may have on people's enjoyment of whichever wine they happen to be tasting, their perception (or better said, their rating) of the more descriptive attributes of a wine, can also be substantially modified by playing music that can be described using the same terms. So, for example, North [25] has demonstrated that music that could be described as 'powerful and heavy', 'subtle and refined', 'zingy and refreshing', or 'mellow and soft' led, at least in undergraduates, to wine being rated as expressing that attribute much more strongly when that music is played than when another piece of music is played, or else when the students tasted in silence. Playing Carmina Burana by Carl Orff, for example, led to a $60 \%$ increase in how 'powerful and heavy' red and white wines ${ }^{2}$ were rated as being, while Nouvelle Vague's 'Just can't get enough' was found to bring out the 'zingy and refreshing' notes in the two wines by a not inconsiderable $40 \%$. While the most appropriate interpretation for these findings is still debated [13, 26], they can, perhaps, best be explained by some form of connotative priming (cf. [27]). The suggestion here is that the metaphorical associations 
with one stimulus (specifically the music) are primed when the drinker is exposed to it. This can then bias their judgments when they are asked about how well a wine expresses, or is associated with, that descriptive attribute. (Of course, one might think of this as a kind of sensation transference; see above.)

Furthermore, given the fact that people have been shown to attach a variety of different meanings, or highlevel concepts, to music (e.g. [28, 29]), it would seem likely that there are probably few limits as to the changes in the descriptive attributes of a wine that could be induced simply by playing the appropriate music (that is, by playing music that primes, or is associated with, similar high-level concepts; concepts such as masculine/feminine, heavy/ light, smooth/rough, expensive/cheap, ethnic/authentic, etc.; cf. [30]).

\section{Music's influence on the analytical aspects of tasting}

Analytic aspects of wine tasting pertain to those attributes that depend on combining multiple sensory and evaluative evaluations, such as judgments of a wine's likely age, complexity, balance, quality, and any assessment of price. Let us start with the most obvious one: price. It has been shown that people purchased more expensive wines at a wine shop while classical music is played versus Top 40 popular music [31] and they also spend more money on food while listening to classical music versus pop or no music [32]. Putting these results together, the assumption is that people would rate a wine as tasting more expensive (and presumably higher quality) if they were to listen to classical music at the same time. Going one step further, according to [33], women would give the wine a higher rating based on the higher assessment of price.

As discussed in one of our previous review articles [13], the assessment of balance in a wine might be easily upset by music (imagine a five-puttonyos Tokaji where the bright acidity and lush sugar levels are in fine balance). On the other hand, according to the Californian wine maker Clark Smith, music can help one find 'sweet spots' in the wine where the various elements are in harmony $[10,12]$.

Complexity in wines refers, in part, to the number of different layers and flavours that a wine might have [34]. While it may seem like a case of metaphoric transfer that more complex music might make a wine seem more complex (or the wine might seem less complex, if the music ends up distracting our attention from the process of tasting the wine), there have been no studies on the subject thus far that we are aware of. Wang and Spence [18] had their participants make complexity ratings while they tasted wine and listened to both congruent and incongruent music. However, in this case, no significant results were obtained in terms of people's complexity ratings regarding the wines that they were tasting. Of course, given the relatively cheap wines used (around $£ 8$ a bottle), it is possible that the wines were fairly simple, and that complexity effects might be observed in a more complex (and presumably expensive) wine.

Given all we know about how wine attributes correlate with musical properties, it seems feasible to compose music that might modify the perception of age in a wine (granted, of course, that one removes any visual cues regarding the colour of the wine; see [23]). Music that emphasize fruitiness, acidity, and astringency might well make a wine seem younger while music that emphasizes smooth texture or secondary/tertiary aromas like woody, earthy, and nutty notes could make a wine seem older. To our knowledge, no one has yet put this suggestion to the test.

\section{Music's influence on the sensory aspects of wine}

Certain pieces of music (or, on occasion, specially composed soundscapes) can modify people's perception of the sensory aspects of wine. Thus far, the research shows that the rated sweetness, acidity, fruitiness, and length of a wine can all be changed by the appropriate musical accompaniment $[12,16,18,35,36]$. Changes in people's ratings of the sensory properties of a wine of up to $20 \%$ are not uncommon. That said, there are several other salient attributes of wine that researchers have yet to demonstrate can be affected by music, including astringency/roughness and alcohol level/viscosity. ${ }^{3}$

\section{Possible mechanisms behind music's influence on the wine- tasting experience}

In terms of how it is that music can influence the tasting experience (especially its sensory aspects), one key hypothesis lies in recent research on the crossmodal correspondences. This is the name given to the surprising associations that people share between seemingly unconnected features, attributes, or dimensions of their sensory experience (see [37, 38], for reviews). So, for example, people have been shown to match sweet tastes with round shapes and tinkling high-pitched piano sounds, whereas bitter tastes are commonly associated with angular shapes and low-pitched brassy sounds instead. There is also extensive evidence to support the existence of a number of crossmodal correspondences between aroma and sound ([39]; see [40], for a review). The suggestion here is that such correspondences, triggered by the background music, may serve to direct our attention to specific attributes within the wine-drinking experience and so make them somewhat more salient (see [13]).

It is, however, important to note that music can also impact on the listener's mood and emotions [41, 42]. This, in turn, can affect what they think about the tasting experience (e.g. $[9,43])$. In addition, if the music gets 
too loud, one may start to see the crossmodal masking of sweetness (and possibly also alcohol) perception and the enhancement of umami perception (see [3] for a review).

Finally, there may be an explanation for the interaction between audition and gustation that is rooted in neuroscience. Neuroimaging has shown that the processing of aesthetic stimuli-be they paintings, music, or food-overlaps within the primary gustatory cortex [44]. According to the researchers working in the field of neuroaesthetics, one explanation for this is that all aesthetic judgements are ultimately based on an evaluation of biological significance, which co-opts the same neural circuitry that appraises the suitability of potential foods/energy sources. Therefore, the fact that our evaluation of music and wine are processed in the same brain area might potentially account for the associations that we make between them, not to mention how the evaluation of one modality might influence the evaluation of the other.

In summary, there is now a broad spread of evidence in support of the notion that what we hear, be it music or soundscape, can impact the hedonic, descriptive, analytic, and sensory aspects of tasting. As summarized above, a number of different mechanisms have been put forward to explain such crossmodal influences. It is perhaps worth noting here that music can impact the descriptive aspects of tasting, without necessarily impacting a person's hedonic or sensory ratings [25]. Meanwhile, in other studies, both the sensory rating of, and the hedonic response to, wine have been affected [16, 18]. Having established the basic phenomenon, one question that soon arises is whether we are all affected to the same extent by music when tasting or evaluating wine.

\section{Is everyone influenced by music to the same extent?}

While some of the anecdotal reports of music's influence on taste have been conducted on wine experts, e.g. wine makers $[9,10]$, it is certainly true to say that the majority of the peer-reviewed scientific research in this area to date has been conducted on social drinkers (often, in fact, students; e.g. $[25,45])$. It would seem plausible to imagine that the judgments of students and other social drinkers might be swayed more by the music playing in the background than the judgments of the wine expert. Such an intuition would certainly fall in line with Deliza and MacFie's [46] suggestion that those who are less confident in their sensory judgments are more likely to be influenced by any taskirrelevant peripheral information (such as the introduction of, or changes to, the background music) than more experienced/confident tasters. What is more, one could also imagine how the trained taster is going to be able to extract more information from the wine (i.e. by sequentially concentrating on any visual clues, moving on to the primary and secondary aromas, then on the wine's structure, and finally making an overall assessment of quality; [34]). Possibly, this might suggest that the wine expert's sensory and analytic judgments should be less affected by music (since their sensory judgments will be less dependent on external information), while their hedonic and descriptive judgments might be more in line with those of the social drinker.

That said, to the extent we can put weight on the anecdotal observations that have been reported in this area [9], it would seem that the wine experts, or musicians for that matter, are influenced in much the same way by what they hear as the social drinker while tasting wine. Indeed, any differences that might emerge probably have more to do with the listener's/drinker's openness to the opportunities provided by the multisensory tasting experience than to anything else. Certainly, it is easy for one to say that the sensory qualities of the wine have not changed while the music changes, when tasting from the same glass (though note how this experimental approach has been successfully utilized in a number of the music-wine-tasting studies that have been published to date; e.g. [17, 36]). Especially relevant here are findings from [47]. These researchers demonstrated that there appears to be a 'unity assumption' when it comes to flavour perception. Specifically, our brains tend to assume that the taste of a beverage in the same container will stay the same unless there are very good grounds for thinking otherwise. Such an assumption of unity presumably also applies to the contents of the wine glass. Indeed, the very fact that significant changes in people's rating of the wine are still reported, despite the fact that the taster knows that the wine itself cannot have changed is, or so we would like to argue here, all the more striking.

As mentioned above, any individual differences in how open people are to the notion of multisensory tasting experiences are certainly worth noting. It is important to stress that such experiences/events are likely not for everyone. In part, it may depend on whether one cares more about analytical tasting; indeed, it would be hard to imagine the famous French oenologist Emile Peynaud, were he still alive, turning up at a multisensory tasting event (e.g. see [48], p. 104). Those who, like Peynaud, spend much of their time trying to taste analytically will likely want the minimum of distractions, so that they can focus their attention on the wine itself. Under such conditions, silence is undoubtedly preferable. However, as we will see below, regular drinkers, by contrast, generally seem to prefer a little music with their wine, especially if it is not too loud (see $[3,16]$ ). They are, after all, usually looking to have the best hedonic experience they can.

\section{Composing music and soundscapes to match the taste of the wine}

While the majority of the studies that have been published to date have tended to pick musical selections from off the 
shelf, this is not always ideal, given that the properties of most pieces of pre-recorded music change from beginning to end. It should perhaps not come as any surprise, then, that we are seeing a growing number of researchers/artists specifically composing music/soundscapes in order to match a certain taste, aroma, or flavour (e.g. [49-54]). In our own research, we have recently started to compare the different sonic compositions that have been created/ composed in order to determine which one best conveys a particular sensory attribute (see [55]). Of course, it is important to bear in mind here that the fact that a particular piece of music (or soundscape) is consistently associated with a particular taste does not guarantee that playing the piece will necessarily impact the tasting experience [13].

\section{Taking a critical look at what experiential experimental events really show}

Wine-music events can vary in intent and delivery, from the more academic tutored wine tastings (e.g. as hosted by the likes of Barry Smith and Charles Spence over the last couple of years; e.g. see $[56,57])$ to events that are purely experiential in nature (e.g. $[35,58])$. Our preference, as experimental psychologists, has always been toward what might be best described as experiential experimental' events. That is, events where the attendees get to enjoy a multisensory tasting experience while, at the same time, contributing data to enhance our (and quite possibly their) knowledge in this area. See Spence et al. [17, 36], Velasco et al. [59], and Wang and Spence [18] for a number of events of this type, together with the empirical/theoretical insights that were gained. It is, however, important to note that there are a number of challenges to bear in mind whenever attempting to conduct experiments in this space.

A sceptic, well versed in the experimental psychology literature, might worry at this point that what is being measured under certain of the experimental testing conditions mentioned above is some form of response bias rather than a genuine perceptual effect. Related here are concerns about experimenter expectancy effects. ${ }^{4}$ The worry is that people might respond in a certain way, not because that is what they really perceive but rather because that is the way that they think they ought to respond, for whatever reason. ${ }^{5}$ One such reason is related to the expectations that the experimenter may have concerning the outcome of the experiment that they are conducting. In order words, people may be responding in the way in which they think the experimenter wants them to.

It could perhaps be argued that experimenter expectancy effects are somewhat more worrying in this kind of experimental design (involving, as it does, a public tasting event). Perhaps people's responses are even influenced by the judgments of other participants around them. ${ }^{6}$ Indeed, over the years, the hopes and expectations of the experimenter have, on occasion, been shown to influence the pattern of results obtained (see, for example, [60-62]). While such concerns are by no means specific to the crossmodal matching or influence of music on wine (see, for example, [63, 64], for a couple of other powerful examples), the public and interactive environments in which such data are collected presumably leave themselves open to such indirect forms of influence.

One other potential concern to bear in mind here is related to the so-called Hawthorne effect. This term refers to the notion that people may respond differently not because of the consequences of the particular intervention that the experimenter has in mind (such as changing the lighting in the original study of the Hawthorne Effect) but because people sometimes respond to the very fact that they are being studied-i.e. that someone is taking an interest in them [65-67]. That said, a quick look at the comments made by some of the participants who took part in Spence et al.'s [36] study concerning the influence of music and/or lighting changes on their perception of the taste of a red wine served in a black tasting glass, would seem to mitigate against such concerns. Indeed, these comments clearly show that a number of the participants came away from the event convinced of the veracity of the phenomenon under study-namely that music and/ or lighting can radically affect the taste of wine. It is hard, we think, for the sceptic to maintain their concern about response bias and experimenter expectancy effects in the light of such first-person reports.

Bearing in mind the small number of participants who chose to leave a comments, what is striking is just how enjoyable surprising, enlightening even, they found the experience. What also comes across very clearly is how subjectively powerful such multisensory experiences can be, even amongst those who were initially sceptical (at least when they are primed to expect that such changes may occur, and to pay attention if they do). Just take the following as representative comments of how the auditory and/or visual environmental changes affected the taste of the wine: 'Brilliant! Was a bit sceptical but it works!'; 'Brilliant!! Definitely changed my perceptions. Who would have guessed?'; 'Fantastic experience. Really interesting. Changed perceptions completely.'; 'Great experience. I didn't think the colour/sound would alter my perception as much as that!? One might even be tempted to say that such unconstrained subjective reports are, in a way, more striking than that of the $15-20 \%$ change in rated fruitiness/sweetness that was documented across the 3000 or so people who took part in the Campo Viejo The Colour Lab over the 4 days that it ran (see [36] for details).

Thus, we certainly believe that such experiential experimental events are a great idea and potentially constitute a relevant way in which to collect large amounts of data. The public's response to such events has, thus far, 
been very enthusiastic (though perhaps the audiences at such events are somewhat self-selecting). That being said, we have observed that it can sometimes be a little confusing/unsettling for the attendees to know where, exactly, to focus their attention (especially in the context of a live musical performance): People appear to be a little unsure as to whether they are at a wine tasting that just so happens to have a live musical accompaniment (in which case they can concentrate on the wine, and probably chat happily amongst themselves) or they are at a music concert where, most unusually, wine is also served (in which case they should respectfully pay attention to the musicians instead). That said, using prerecorded music normally resolves this issue in favour of people's attention being directed primarily to the wine. What also seems to help is to explicitly instruct the attendees to mindfully attend to the two distinct streams of their experience (something we are not necessarily all that used to doing in everyday life!) and to search out the connections, or correspondences, between hearing and taste.

\section{Interim summary}

So, having hopefully convinced the sceptic (e.g. $[10,11])^{8}$ of the potential crossmodal effect of music on the taste of wine (not to mention the wine tasting experience), and of the appropriateness of experiential experimental events for furthering our knowledge in this area, the next question to address is 'Why should we care?'. We certainly believe that the evidence that has been briefly summarized here, and which was reported in detail in a previous article (see [13]), provides sufficient grounds for thinking that what is going on here is about so much more than merely enhancing the taste of a mediocre wine (or covering up its flaws) through 'sonic seasoning'. It is our contention that our perception of any wine can be influenced by what we happen to be listening to at the same time. What is more, these effects seem to influence everyone from the social wine drinker through to the wine expert $([9,56,57])$. Given such a backdrop, it should come as little surprise that there has been a great deal of interest in this area (i.e. incorporating a sonic element into tasting experiences) ranging from marketers to artists all the way through to some healthcare professionals. Furthermore, the emergence of sensory apps is providing an increasingly attractive route for many brands to try to enhance the wine drinking experience by means of carefully selected musical matches (e.g. $[68,69])$. There are, then, a number of directions that look especially promising when it comes to applying the crossmodal findings regarding music's influence on taste, as well as the odd red herring. ${ }^{9}$ In the sections that follow, we will review a number of commercial, artistic, clinical, and entertainment-related uses to which such sensory insights have been put thus far.

\section{On the commercial use of music to influence consumer drinking behaviour}

Here, it is worth noting that music has been used to influence consumer behaviour for many years now. ${ }^{10}$ Timeand-again, researchers have demonstrated how modifying the auditory attributes of the drinking environment can bias both consumer choice and drinking behaviour: So, for example, consumers spend more on wine when classical music, rather than Top 40 music, is playing in the wine store [31, 32]. People also buy more French wine in the supermarket when French accordion music is playing rather than when German Bierkeller music is played [70, 71]; the pattern of sales reserving when distinctively German music is played instead (cf. [72]). Equally powerful, from a commercial point of view, are those findings suggesting that the rate at which people drink, and how long they stay in a given venue, is modulated by the tempo and loudness of the music that happens to be playing in the background [73-75]. Finally, there is evidence that the volume of the music can serve to attract potential consumers to (or repel them from) specific drinking environments ([76]; see $[77,78]$ for reviews). On the topic of volume, we have already seen that overly loud music can interfere with the taste of the drinks, and there is evidence that many consumers are increasingly starting to rebel against noisy restaurant environments [3, 79]. While such crossmodal effects of music on consumer choice and drinking behaviour are fairly well-known, here, we wish to focus on the more specific influence of music/ soundscapes on the tastes of wine.

\section{Who is utilizing the insights regarding the influence of sound on wine tasting?}

A few years back, David Williams, then deputy editor of The World of Fine Wine, suggested that we might soon find 'music lists' accompanying the wine lists in Michelin-starred restaurants $[8,80]$. While Williams may well have had his tongue stuck very firmly in his cheek when making this suggestion, ${ }^{11}$ something not too far removed has recently been taking place in The Auricle Sonic Arts Gallery in Christchurch, New Zealand. In particular, Jo Burzynska (http://stanierblackfive.com/curating-the-worlds-first-sound-and-wine-list/) has been curating a monthly wine list to match (or complement) the sound exhibition in the gallery and the music playing in the space. It has been described in the press as the world's first sonic wine bar (http://www.radionz.co.nz/ national/programmes/morningreport/audio/20144923/ new-zealand's-first-wine-and-sound-bar-opens-in-christ church).

There are obviously a number of challenges here when it comes to trying to match the music to the wine in a restaurant setting. Rarely, except perhaps at a tutored winetasting, or at a single sitting tasting menu in a restaurant 
with wine pairings, will everyone be drinking the same wine at the same time? Can anything be done, then, to provide a more individualized sonic solution for the wine drinker? One solution, though currently technically and/or financially challenging, involves the use of hyperdirectional loudspeakers, that is, loudspeakers that project sound in a narrowly defined direction (think auditory searchlights), so they could potentially be mounted one over each table to provide individualized soundscapes. Another innovative solution here involves the use of digitally augmented glassware (see [81, 82], for predictions along these lines). The idea here is that the drinking vessel itself is turned into a loudspeaker, so the drinker hears the music coming from inside their glass. ${ }^{12}$ Incorporating a gyroscope into the glassware would further allow the music to be heard only when the drinker lifts the glass off the table and tilts it toward their lips.

\section{Sonic (or digital) ${ }^{13}$ seasoning}

Taking things one step further in terms of personalizing the wine-music match, it is widely known that we all live in somewhat different taste worlds [83, 84]. Hence, it is not uncommon to find that what you like, I detest, and what I adore you are indifferent to (see [85] for a summary of such individual differences). While the causes of such individual preferences are manifold, the key point to note for our discussion here is that the world of wine appreciation is no less contentious (even amongst top wine writers, see [86]). Hence, there would seem to be a very real possibility that, on opening a given bottle of wine, tasters may come to very different conclusions about whether they like it or not and even how good the wine is. For one person, the wine might be too fruity, while another might find the tannins too aggressive. Now, if this kind of disagreement happens with what's on our dinner plates, it is normal for people to reach for the salt, the pepper, and perhaps a host of other condiments to season our own food. When it comes to wine, however, there is nothing to be done.

Here, then, we could think about using some sonic seasoning to shift our perception of the sensory, hedonic, analytic, and/or descriptive attributes of the wine a little further in the direction of our own personal preferences. So, perhaps, one could imagine someone playing a little 'sweet' music to mute the tannic astringency in a young oaked Rioja (see [36] for evidence on this score; see also [12]). It really does not seem too farfetched, then, to suggest that on finding ourselves with a glass of wine that, for whatever reason, does not quite match our sensory preferences, we might as well reach for the sound system to 'season' the wine.

\section{Experiential events}

The last few years have seen the rapid growth of multisensory experiential events, where the public are invited to taste wine while listening to matching (or, on occasion, mismatching) music. One such event took place on the 24 October, 2013 at St. Luke's Church in central London. Five musicians from the London Symphony Orchestra played live in front of an audience of well over 100 guests who tasted four wines (provided by the Antique Wine Company) that had been identified in prior research to match the musical selections especially well [16]. Many other music and wine events, both large and small, have been taking place around the world over the last couple of years: For instance, the enologist and food engineer Stella Vassiliki has organized a number of such events over in Crete, Greece (see https://www.dopios.com/experiences/ greece/heraklion/1951-what-is-the-sound-of-wine). Meanwhile, in February 2015, Ben Houge came to Oxford's 1855 Wine Bar \& Kitchen and presented the audience gathered there with a series of musical soundscapes that evolved continuously to match the various carefully selected wines that the audience got to taste during the evening [49]. Other notable multisensory events involving wine-tasting while listening to matching classical music have been organized over in Germany by Martin Sachse-Weinert [87]. Finally, Jo Burzynska working out of Christchurch, New Zealand, has also been very active in organizing a number of music-wine events (e.g. http://stanierblackfive.com/oeno sthesia-sound-and-wine/; http://auricle.org.nz/mishearingsby-jo-burzynska/).

\section{Sensory apps}

A second area where music and taste are increasingly being brought together is in sensory apps. The champagne house Krug, for example, recently launched its Music Pairing series (https://www.krug.com/; [69]). With this app, the consumer can scan their wine label, or else type the individual number appearing on the back of their bottle, in order to access a selection of music that has been chosen to match the specific wine. According to Jones, 'Krug's "Music Pairing" has recording artists select their picks for tracks to accompany six particular varieties of Champagne, much like a chef would note what food pairs best with a particular wine'. At present, the musical matches that are offered are idiosyncratic, as highlighted by the following quote from Argentine pianist, Marcela Roggeri: 'There are certain champagnes that I associate only with classical music like Krug Clos du Mesnil or Krug Clos d'Ambonnay. However I could associate other Krug champagnes with jazz or Brazilian music, such as Krug Rosé.' [68]. ${ }^{14}$

Another intriguing sensory app that paired music with aroma was developed by Courvoisier-the $\mathrm{Le} \mathrm{Nez} \mathrm{de}$ Courvoisier app (see http://appcrawlr.com/ios/le-nez-decourvoisier [accessed 29 July, 2013]). The aim in this case was somewhat different from that of Krug's Music Pairing app. In Corvoisier's case, the app enabled 
some of the brand's premier customers to try and match a piece of music with each of the six key aromas in their XO Imperial Cognac. While the musical matches in this case were not perfect-that is, when we tested people's ability to match the musical selections with the aromas in an experimental setting, they were less than perfect at picking up on the intended match [52]. The idea underlying this app was, however, an intriguing/engaging one, where the structured musical backdrop would help the consumer to experience the sequential development of the different aromas in the drink itself. Furthermore, once the customer had acquired the correspondence between the sound of say, the harp and the aroma of candied orange, they could then enjoy a glass of the cognac while listening to another piece of music with the same sonic elements.

Given the growing commercial interest in this area, one could easily see how, in the years to come, a wine brand might offer a sensory app that would allow the user to pick specially pre-selected music to match a given wine, or to add a dose of digital/sonic seasoning. There is now certainly a sufficient body of scientific evidence on which to start basing the design of such sensory apps. Ideally, these apps will also offer musical solutions to match the taste of the wine, no matter what the type of music we prefer, be it rock, jazz, opera, or drum and bass. ${ }^{15}$

\section{Clinical applications}

The growing popularity of sonic seasoning, mentioned above, has drawn increased interest from healthcare professionals interested in using all the senses (including music) to enhance the taste perception of those in special need (e.g. think only of the ageing population suffering from a deterioration of their sense of taste and smell, chemotherapy patients, etc.). Moreover, various agencies are now looking at using specialized soundtracks to fight obesity, by using soundtracks, or even musical playlists, that evoke sweetness to deliver the same satisfaction in reduced-sugar foods [88]. One important note of caution here, though, is that no one has, at least not as far as we are aware, assessed how long lasting some of these crossmodal effects are. This would certainly seem like an important prerequisite before going too far down this line of application.

Going back to specifically music and wine, not only can music enhance the enjoyment of wine, but another fascinating area of research would involve using music to curb alcoholism or regulate alcohol consumption. It has already been shown that the tempo of background music can influence the rate of consumption [75]. We can certainly imagine sensory apps where, mismatching music is played to make the wine taste more unpleasant, when one has already had enough to drink.

\section{Wine-music matching: it is not just about the wine or the music}

Everything that we have seen thus far in this piece and in the two articles that preceded it $[13,89]$ has been about the wine: How to match wine with music, and how the right musical selection can change the hedonic, descriptive, analytic, or sensory attributes of the wine itself. One might, naturally, wonder whether any beneficial effects of matching also occur in the other direction: That is, would people's appreciation of the music, or soundscape, be enhanced, if listening while tasting a matching drink? The evidence reported earlier, explained in terms of processing fluency, might lead one to suggest that this should, in fact, be the case. However, as yet, there has been little research conducted specifically to assess people's responses to auditory, or for that matter, visual stimuli as a function of stimulating the chemical senses in different ways. So, having pointed to this as an intriguing area for future research, what we would like to do in this final section is to highlight a number of other reasons for wanting to pair wine tasting/ drinking with the right musical accompaniment, other than merely to change the way in which people respond to the individual components that make up the sensory experience (be it the wine or the music/soundscape).

\section{Stressing the similarity between composing music and making wine}

One reason why some people (or brands) have wanted to bring music and wine together is to stress the similarities in the art (or is that science?) of composing great music and great wine. ${ }^{16}$ That, certainly, would seem to have been the idea behind a 4-day event in April, 2014, organized by the champagne house Krug, together with the London Philharmonia Orchestra. In this event, the musicians played via digital installation/link Stravinsky's 'The Rites of Spring' to celebrate one of their champagnes. The aim in this case was to highlight the 'parallels between conducting a symphony orchestra and composing Krug Grande Cuvée' [58]. A similar point was made by Argentine pianist Marcela Roggeri when talking about her playlist for the Krug music app, when she pointed to the fact that: 'The world of music and the world of champagne share a common vocabulary: precision, expressiveness, roundness,' [68]. Clark Smith, whom we have come across already, has also given a presentation at the AWITC back in 2007 on this theme (see http://www.postmodernwinemaking.com/wine-and-music).

On the other hand, not everyone agrees that such comparisons are necessarily appropriate here. Indeed, as we saw in an earlier article [13], the philosophers have argued against any attempt to compare great music and great wine, with some commentators stridently asserting that there are no 'taste-symphonies and smell-sonatas' ([90], p. 99). This has been qualified by Tefler ([91], p. 20), who states that 
'Symphonies and sonatas are exceedingly complex works of art. He should have asked whether there can be tasteand-smell preludes, and the answer is by no means so obvious'. Tefler ([91], p. 22) goes on to say that 'It is said that a chord in music, for example, is unlike a combination of flavours. A chord in music has both form (in the spacing of the pitch of the notes) and timbre (the characteristic quality of the sounds produced by the musical instrument or instruments), but flavours have only something analogous to timbre ([92], pp. 243-244)'. In the end, what is clear is that, regardless of the formal appropriateness of doing so, comparing music and wine making is an interesting exercise for people to think about (see [93] for an example of North Indian music instruction via food metaphors).

\section{The extraordinary emotional response}

A second aim of wine-music events that is not directly related to changing the taste of the wine is to elicit an extraordinary emotional response. In particular, on occasion (and thus far it is only on occasion), some of those who experience the combined multisensory input of a certain taste/flavour experience together with a particular piece of music, soundscape, or even a tone, have had strong experiences that go far beyond what one would have expected merely from combining individual response to the taste and to the sonic stimuli. The first hint that something special, superadditive even [94], might occur when sound and taste are combined in the right way was reported by Kristan Holt-Hansen in the late 1960s. In his seminal early work, Holt-Hansen [95] demonstrated that people would match Carlsberg Elephant lager to a higher-pitched sound than regular Carlsberg lager (640-670 vs. $510-520 \mathrm{~Hz}$, respectively, perhaps because of its higher alcohol content; see also [96]). A few years later, Holt-Hansen [97] brought a new group of participants, all students, back into the lab. $\mathrm{He}$ gave them six different lagers and ales to taste (though he coyly refuses to name the brands). Once again, the participants had to report the frequency at which harmony was experienced. As in his earlier study, the beer apparently tasted better at the pitch of harmony than when evaluated in silence. Intriguingly, given our earlier discussion [13], when the frequency of the pulsed tone was changed, the beers also changed, with some of the participants saying that they tasted watery, strong, bitter, etc. However, the most interesting thing here is the fact that three of the nine participants also reported having extraordinary experiences at the pitch of harmony. Here are some of the quotes from those who took part in the study:

The tone turned into a tune. Thrills of pleasure ran through my body.

I felt as if my head was expanding in all directions.
My right hand with the glass of beer in it trembled so violently that I was suddenly afraid of dropping the glass. I felt as if I was floating in the air. The tone was intensified to such a degree that it sounded like a symphony orchestra and the room was filled with it. My jaws were moving in and out with the rhythm of the tone.

The tone expanded and became wonderfully sonorous. (all from [97], p. 1026).

Interestingly, Holt-Hansen [97] talks of the sensations of sound and taste becoming unified at the pitch of fit/ harmony. These sensations are different from the experience of separate sensations (of taste and of hearing) at other, non-matching, frequencies (cf. [98]). ${ }^{17}$ Now, these results can be read in a number of ways: On the one hand, some of the above quotes sound so bizarre that you might well be tempted to wonder what else the participants had been taking (the study was, after all, published at the end of the swinging 60s). ${ }^{18}$ Indeed, when Rudmin-Cappelli [99] attempted to replicate and extend Holt-Hansen's early results, he was only able to replicate the crossmodal matching of pitch with taste/ flavour. That is, none of the participants in the latter study experienced any surprising experiences at or around the mystical 'pitch of harmony'.

Alternatively, however, this seems to have been the stance taken by many psychologists over the intervening years, you might simply wonder whether it is really worthwhile to ask one's participants what they truly think or feel! For those who share this view, it may be time to reassess the scepticism that psychologists have held for so long about the value of subjective reports (see [100]). Such reports were, in a way, such a striking aspect of Holt-Hansen's [97] paper, which it would seem somehow wilfully negligent to ignore them completely, especially when one sees something similar (i.e. an extreme emotional response) emerging subsequently in some very different contexts. For instance, as we saw earlier, the unconstrained subjective reports also constituted a powerful element in the results reported by Spence et al. [36].

Away from the world of alcohol, diners at Heston Blumenthal's The Fat Duck restaurant in Bray (http:// www.thefatduck.co.uk/) have also been known to experience an extreme emotional reaction. In this case, diners have broken into tears on being presented with the signature dish at the restaurant, 'The sound of the sea' [101, 102]. This particular dish comes to the table looking like the sea, with what appears to be sand, foam, seaweed, and seafood. At the same time as the dish is placed before the diner, the waiter offers the diner a conch shell, out of which emerges a pair of earbuds. The waiter instructs the diner to insert the earbuds before they start the dish. On so doing, the diner hears the sound of the 
waves crashing on the beach and seagulls squawking overhead.

The multisensory experience that ensues has brought some diners to tears [102]. Once again, this is not something that normally happens when people hear the sounds of the seaside, nor when they eat seafood, no matter how beautifully it has been prepared. In other words, it would seem to be something about the combination of matching taste and auditory sensations that is so powerful (at least for some). Note here that trying to deliver the same emotional hit simply by using a very emotionally charged soundtrack ${ }^{19}$ may not achieve quite the same goal.

A third example of the striking emotional response that can sometimes be seen when the ear and the flavour senses are appropriately stimulated together was documented at the 2015 Campo Viejo Streets of Spain event in London. At this popular street festival, people had the opportunity to taste three wines while listening to the matching soundscapes, which had been specially composed to match each of the wines. Sarah Knapton, one of the first journalists to report on the experience noted that '...the experience appears to take wine drinking to a new emotional level. The first volunteers to try listening to the scores while drinking said they felt transported to a different place. Others wept.' ([35], p. 7).

Thus far, we have observed crying as a common reaction for those select few who experience strong tastemusic experiences. According to some, the act of crying may indicate an insightful artistic experience, one where an initial discrepancy between expectation and reality resolves itself after a change of schema/expectations/world view (see [103]). Might it be possible that the participants who listened to the sound of the sea while eating their seafood dish, or listened to matching soundscapes while drinking wine, experienced such a change of mental framework (e.g. from the expectation that music and taste are separate entities, to the sudden, or growing, realization that music and taste are one) that it resulted in tears?

Given what was mentioned earlier, namely that eating and listening to music (or any aesthetic process, for that matter), apparently have similar neural underpinnings, then perhaps we can see these strong emotional experiences as rather extreme examples of processing fluency. Normally, congruent stimuli make it easier for participants to evaluate the sensory properties of both stimuli (i.e. higher processing fluency) and hence make the component stimuli more pleasant [21]. In the case of wine-music pairings that go especially well together, listening to the music while tasting the wine might be so easy and fluently pleasurable that they break out into tears. Alternatively, intense aesthetic experiences have been shown to activate the default mode network, a region associated with self-referential thoughts
[104]. Perhaps then, these food-music pairing experiences resonated strongly with the individuals in question (perhaps those who wept while eating the Sound of the Sea had strong ties to the beach) that they were moved to tears.

\section{Appreciating the effort that has gone into the designed experience}

One final point to consider before closing concerns the extent to which the target audience's appreciation of the effort that has gone into the matching of sonic and taste stimulation might contribute to their emotional response. Indeed, work on the impact of artistic plating on people's rating of food has highlighted how a part of the value of artistic plating may be linked to the obvious effort that has gone into the preparation and presentation of the food (see [105]). Something very similar may be going on in the case of wine-music/soundscape events when the drinker (or taster) realizes that someone has gone to the trouble of carefully selecting a particular auditory backdrop to accompany the tasting experience. Indeed, in a recent chocolate/music pairing study, we were able to demonstrate that a particular musical selection had a much greater impact on people's tasting experience (specifically their ratings of an artisanal chocolate) when they were told that the music had been the chocolatier's inspiration for the dish (see [106]). Something similar may have been happening to the attendees of the 2015 Campo Viejo event.

\section{Interim summary}

Taken together, it can be argued that the three example of strong emotion experiences reported above (one from the laboratory, one from the restaurant, and one from a large-scale multisensory experiential event), while rare in their occurrence, nevertheless do highlight how getting the sound-taste combination just right can deliver an experience that would appear to be so much richer, or more powerful, than the sum of the individual sensory experiences. What is more, the value in combining the senses in this way starts to shift in focus from merely just wanting to enhance the tasting experience (as far as the food or drink is concerned), to trying to deliver a powerful emotional experience to those whose senses are being stimulated. Of course, as we have seen clearly in everything that has been reviewed so far, such emotional experiences are extremely rare. It is, though, presumably only by gaining a better understanding of the mechanisms that underlie the crossmodal interactions between music/soundscapes on the one hand, and tasting experiences on the other, that we can hope to increase the likelihood that the design of any given multisensory tasting experience will be capable of delivering such a powerful emotional hit on a somewhat more regular basis. 
And when it comes to engineering unusual emotionally affecting experiences, it may be that the artists (culinary and otherwise) and experience designers are actually much better placed to turn the insights and constraints thus far identified by the scientists and commentators into truly engaging multisensory tasting experiences (e.g. see $[107,108]$ for a number of fascinating examples in the multisensory design space). Certainly, the artist might well appreciate the extreme emotional response to a given environment, such as one's target audience breaking into tears, more than the psychologist (whose first thought might well be what the ethics panel would say), and who still find it difficult to deal with such unconstrained subjective report data (see [100]), that is, data that falls beyond the limits of their carefully constrained scoresheets and line scales (and we include ourselves within this criticism).

\section{Conclusions}

As the research that has been reviewed here has hopefully made clear, there are a number of reasons as to why we should all care about the fact that music changes the experience of tasting wine. What is more, these reasons extend well beyond merely wanting to change the sensory-discriminative, descriptive, analytic, and/or hedonic aspects of tasting. Music has also been paired with wine in order to highlight the analogies in terms of the act of creation of both music and wine and the harmonies present in both (see also [109]). As has become apparent from this review, the scientific approach to the matching of music to wine based on the theory of crossmodal correspondences is but one of many approaches. There is also widespread interest in the idiosyncratic matches of particular individuals, including those who are synaesthetic [35], just do not expect the music to necessarily change the taste of the wine. Finally, the area of the extraordinary experiences that can sometimes (albeit very rarely) be elicited by stimulating multiple senses in a congruent, or matching manner, is certainly also something of interest for the future (though, as we have seen, the experimental psychologists working in this area may need to change their dependent measures in order to capture such effects).

As this brief review of the application of such research findings has made clear, the growing realization of just how profound an experience can be elicited by certain music-wine combinations is being taken up by people working in a number of different areas. Such experience design goes far beyond traditional marketing approaches that have focused merely on how the specifics of the music can influence which type of wine we choose to buy, and how much we are likely to spend, not to mention how quickly we drink and even whether or not we will choose to enter a certain bar or not (see [77, 78, 82] for reviews).

And, finally, while the focus in this review has primarily been on the world of wine, it is worth noting that similar interventions are now being extended to a variety of other food and beverage (both alcoholic and nonalcoholic) items. In fact, over the last 5 years or so, there has been something of an explosion of multisensory tasting events and/or apps designed to change people's perception of the taste of everything from coffee to cocktails ([38, 110-112]) and from whisky to vodka as well (e.g. $[59,113])$. And, of course, once one has started down the road to multisensory experience design, there seems little reason to stop with just changing the music/soundscape. Indeed, many of the more recent examples of multisensory experience design have incorporated changes to both the lighting and the music or soundscape (see [36, 59, 113]; see also [82]; http://concreteplayground.com/ auckland/food-drink/drink/this-pop-up-bar-of-dreams-sp ecialises-in-breathable-booze/; http://edition.cnn.com/20 14/09/18/tech/innovation/multi-sensory-organ/index.htm l?hpt=hp_c5), and, on occasion, to the other senses as well (e.g. [114]).

\section{Endnotes}

${ }^{1}$ The literature on crossmodal correspondences provides a somewhat ambiguous conclusion as far as this question is concerned (see [115])

${ }^{2}$ In this case, the wines retailed at around $£ 10$ a bottle.

${ }^{3}$ Stafford et al. [116] has found that alcohol strength can be impaired by distractor conditions involving listening to music while hearing and repeating news stories.

${ }^{4}$ Concerns, in fact, that run throughout much of the field of experimental psychology (e.g., [63, 64]), but which most psychologists conveniently seem to ignore (after all, making sure that all of one's experiments were conducted in a double (or even triple) blind manner, as in a clinical drugs trial, just seems like it is more trouble than it is worth). Who knows though whether it is all those null results, and all those failures to replicate, sitting in the psychologist's file drawers [117] somehow mitigate against experimenter expectancy effects being as much of a concern as some would have us believe!

${ }^{5}$ There might also be something about the design of the experiment that might also lead to this kind of bias in the way that people (one's participants) respond [118].

${ }^{6}$ Which is why we have started changing our experimental design such that participants sitting near each other do not perform the same task. For instance, we might have multiple forms of the questionnaire with different orders of wines to be tasted, so for the same music stimuli, one would be rating a different wine than one's neighbours (see also [119], for an example of such an approach being used). 
7،... totally changed my taste perceptions.'; '... really showed me the influence of environment to taste.'; '... definitely noticed difference with/without sound.' 'OMG. Can't believe it is same wine'; 'Amazing how the same drink tastes so different'; 'Quite bizarre! Such different flavours!'; 'I couldn't have expected such a different change of taste'; 'Can't believe how much taste changed.' What is also interesting given our earlier discussion about the speed at which such environmental atmospheric effects kick in [13] was the following: 'Fascinating! Flavour/colour connection: The change was instant. How curious!' And, finally here, echoing Spence et al.'s [16] findings that people enjoy wine more with music that in silence 'Yes, I liked the wine more with the music!!'

${ }^{8}$ Here, is Gray's [10] description of how he was won over by a demonstration by Clark Smith in Santa Rosa, California: '...I brought two winemaker friends. The idea was to have allies in case I disagreed with Smith-which, as a hard-core cynic, I expected to do'.

${ }^{9}$ Talking of red herrings, some wine-makers have started playing their wines music while they mature in the cellar. Just take the following from Aurelio Montes, the Chilean winemaker who sponsored North's [25] study: 'I've always believed that playing Gregorian chants aids the angelic maturation of our wines and is an important step in our wine making process.' [80]. The press certainly love to report on such winemakers who argue that playing music in the cellar has a beneficial effect on the maturation of their wines [120]. While we are by no means experts in the area, nothing that we have come across thus far suggests that such behaviours have any effect whatsoever on the taste, or development, of the wine in the bottles so serenaded. We find ourselves rather more in alignment with Werner Gruber, a physicist from the University of Vienna, whose only comment on the idea, when proposed by Austrian winemaker Markus Bachmann, was 'Rubbish' [120]. That said, for those who still want to try some of the sonically enhanced wines, just look out for Sonor Wines (http://www.sonorwines.com/de/home.html). Recent offerings from them have included a 2010 pinot blanc infused with Mozart's $41^{\text {st }}$ Symphony and a 2010 Zweigelt that was played a selection of arias.

${ }^{10}$ There has certainly long been a commercial interest in the use of music in commercial environments 'to manipulate' people's behaviour (see [121] for a review).

${ }^{11}$ And anyway, it is a debatable point as to whether you would want your music to match the food or to match the wine in the typical restaurant setting [51, 122].

${ }^{12}$ Intriguingly, Diageo's Johnnie Walker brand recently developed glassware to deliver music to the drinkers via vibrations directed to their inner ears when their teeth happened to touch the glass [123].
${ }^{13}$ Digital, because most of the instantiations of this kind of sonic stimulation will be digitally mediated [81, 82].

${ }^{14}$ Pete Brown, takes a similarly personal and idiosyncratic (and no, we do not mean synaesthetic!) approach to matching music to the taste of different beers [124].

${ }^{15} \mathrm{Be}$ aware, though, that the sonic solutions that will be developed in the coming years will likely span the spectrum from pure marketing-led interventions through to solidly empirically researched apps [110].

${ }^{16}$ The idea of bringing together music and food, to use one to inform the process behind the other, is not as odd as it seems. There is, after all, a long-standing tradition in Indian music of describing the balance of various musical motifs in a composition using food metaphors, such as the balance between a spicy samosa and sweet chutney [93].

${ }^{17}$ According to Von Hornbostel ([98], p. 214), 'What is essential in the sensuous-perceptible is not that which separates the senses from one another, but that which unites them; unites them among themselves; unites them with the entire (even with the non-sensuous) experience in ourselves; and with all the external world that there is to be experienced.'

${ }^{18}$ The similarity was not lost on Holt-Hansen himself. As he put it, some of the experiences described by his participants resembled 'those described by persons under the influence of such drugs as mescaline, psilocybin, and cannabis.' ([97], p. 1023). This despite the fact that during their 1-h experimental session, not more than 12 fluid ounces (that is, $360 \mathrm{ml}$ or less) of beer was consumed by each participant.

${ }^{19}$ As embodied in the 'Messi's Goal' dessert served at the El Celler de Can Roca restaurant in Spain (see [125]; [82], pp. 316-317).

\section{Competing interests}

The authors declare that they have no competing interests.

Authors' contributions

CS and Q(J)W wrote all parts of this review. Both authors read and approved the final manuscript.

\section{Acknowledgements}

CS would like to acknowledge the AHRC Rethinking the Senses grant (AH/L007053/1)

Received: 21 August 2015 Accepted: 15 December 2015

Published online: 24 December 2015

\section{References}

1. Pettit LA. The influence of test location and accompanying sound in flavor preference testing of tomato juice. Food Technol. 1958;12:55-7.

2. Srinivasan M. Has the ear a role in registering flavour? Bull Cent Food Technol Res Inst Mysore. 1955;4:136.

3. Spence C. Noise and its impact on the perception of food and drink. Flavour. 2014;3:9.

4. Spence C. Music from the kitchen. Flavour. 2015:4:25

5. Spence $C$. Eating with our ears: assessing the importance of the sounds of consumption on our perception and enjoyment of multisensory flavour experiences. Flavour. 2015;4:3. 
6. Anon. Synaesthesia: Smells like Beethoven. In: The Economist. 2012. http:// www.economist.com/node/21545975. Accessed 15 August 2015.

7. Antin C. What does wine sound like? 2014. http://punchdrink.com/articles/ what-does-wine-sound-like/. Accessed 6 August 2015.

8. Reid M. How Guns \& Roses can change your tune on wine. In: TimesOnline. 2008. http://journalisted.com/article/b725. Accessed 9 August 2015.

9. Crawshaw A. How musical emotion may provide clues for understanding the observed impact of music on gustatory and olfactory perception in the context of wine-tasting. Unpublished manuscript. 2012.

10. Gray WB. 'Enter Sandman' with Cab? Road testing Smith's theories. In: San Francisco Gate. 2007. http://www.sfgate.com/wine/article/Enter-Sandman-withCab-Road-testing-Smith-s-3235605.php. Accessed 13 August 2015.

11. Jones A. A far from vintage show as Callow uncorks the clichés. 2012. http://www.independent.co.uk/arts-entertainment/tv/features/the-week-inradio-a-far-from-vintage-show-as-callow-uncorks-the-clich-s-8269761.html. Accessed 3 August 2015

12. Smith C. Astringency and harmony in tannins. In: Wines \& Vines. 2010. http://www.winesandvines.com/template.cfm?section=columns_ article\&content=78078. Accessed 8 July 2014.

13. Spence C, Wang QJ. Wine \& music (II): can you taste the music? Flavour. 2015:4:33.

14. Sachse-Weinert M. Wine \& musik: $2+2=5$ [Wine \& music: $2+2=5$ ]. Vortrag im Rahmen der Ringvorlesung "Weinwissenschaft" an der Johannes Gutenberg-Universität Mainz im Sommersemester. Presentation given on 4th July. 2012.

15. Gray WB. Music to drink wine by: Vintner insists music can change wine's flavors. In: San Francisco Chronicle. 2007. http://www.sfgate.com/wine/ article/Music-to-drink-wine-by-Vintner-insists-music-can-3235602.php. Accessed 13 August 2015.

16. Spence C, Richards L, Kjellin E, Huhnt A-M, Daskal V, Scheybeler A, et al. Looking for crossmodal correspondences between classical music \& fine wine. Flavour. 2013;2:29.

17. Spence C, Velasco C, Vanne M, Hopia A. Can you taste the music? In: Hopia A, Ihanus S, editors. 5D cookbook. Seinäjoki: KUMURU-project. 2014. p. 73.

18. Wang QJ, Spence C. Assessing the effect of musical congruency on wine tasting in a live performance setting. i-Perception. 2015;6:1-13.

19. Seo HS, Hummel T. Auditory-olfactory integration: congruent or pleasant sounds amplify odor pleasantness. Chem Senses. 2010;36:301-9.

20. Labroo AA, Dhar R, Schwartz N. Of frog wines and frowning watches: semantic priming, perceptual fluency, and brand evaluation. J Consum Res. 2008:34:819-31.

21. Winkielman P, Schwarz N, Fazendeiro T, Reber R. The hedonic marking of processing fluency: implications for evaluative judgment. In: Musch J, Klauer KC, editors. The psychology of evaluation: Affective processes in cognition and emotion Mahwah: Lawrence Erlbaum. 2003. p. 189-217.

22. Krishna A, Elder RS, Caldara C. Feminine to smell but masculine to touch? Multisensory congruence and its effect on the aesthetic experience. J Consum Psychol. 2010;20:410-8.

23. Spence $\mathrm{C}$. The price of everything - the value of nothing? World Fine Wine. 2010;30:114-20.

24. Cheskin L. How to predict what people will buy. New York: Liveright; 1957.

25. North AC. The effect of background music on the taste of wine. Br J Psychol. 2012;103:293-301.

26. Spence C, Deroy O. On why music changes what (we think) we taste. iPerception. 2013:4:137-40.

27. Walker P. Cross-sensory correspondences and naive conceptions of natural phenomena. Perception. 2012:41:620-2.

28. Rigg MG. An experiment to determine how accurately college students can interpret the intended meanings of musical compositions. J Exp Psychol. 1937;21:223-9.

29. Watt R, Quinn S. Some robust higher-level percepts for music. Perception. 2007;36:1834-48

30. Yeoh JPS, North AC. The effects of musical fit on choice between two competing foods. Music Sci. 2010;14:127-38.

31. Areni CS, Kim D. The influence of background music on shopping behavior: classical versus top-forty music in a wine store. Adv Consum Res. 1993;20:336-40.

32. North AC, Shilcock A, Hargreaves DJ. The effect of musical style on restaurant customers' spending. Env Behav. 2003;35:712-8.

33. Almenberg J, Dreber A. When does the price affect the taste? Results from a wine experiment. SSE/EFI Working Pap Ser Econ Finance. 2010;717:1-16.
34. Fielden C. Exploring the world of wines and spirits. London: Wine \& Spirit Education Trust; 2009.

35. Knapton $\mathrm{S}$. Why sparkling wine sounds like beans falling on a plastic tray. In: The Daily Telegraph. 2015. http://www.telegraph.co.uk/news/science/sciencenews/11577381/What-does-wine-sound-like-Youre-about-to-find-out.html. Accessed 2 May 2015.

36. Spence C, Velasco C, Knoeferle K. A large sample study on the influence of the multisensory environment on the wine drinking experience. Flavour. 2014;3:8

37. Spence C. Crossmodal correspondences: a tutorial review. Atten Percept Psychophys. 2011;73:971-95.

38. Spence C. On crossmodal correspondences and the future of synaesthetic marketing: matching music and soundscapes to tastes, flavours, and fragrance. In: Bronner K, Hirt R, Ringe C, editors. (((ABA))) Audio Branding Academy Yearbook 2012/2013. Baden-Baden: Nomos; 2013. p. 39-52.

39. Belkin K, Martin R, Kemp SE, Gilbert AN. Auditory pitch as a perceptual analogue to odor quality. Psychol Sci. 1997:8:340-2.

40. Deroy O, Crisinel A-S, Spence C. Crossmodal correspondences between odors and contingent features: odors, musical notes, and geometrical shapes. Psychon Bull Rev. 2013;20:878-96.

41. Juslin PN, Sloboda JA. Handbook of music and emotion: theory, research, applications. Oxford: Oxford Unviersity Press; 2010.

42. Konečni VJ. Does music induce emotion? A theoretical and methodological analysis. Psychol Aesthet Creat Arts. 2008;2:115-29.

43. Smith BC. The emotional impact of a wine and the Provencal rose paradox. Unpublished manuscript, 2009.

44. Brown S, Gao X, Tisdelle L, Eickhoff SB, Liotti M. Naturalizing aesthetics: brain areas for aesthetic appraisal across sensory modalities. Neuroimage. 2011;58: 250-8.

45. Henrich J, Heine SJ, Norenzayan A. The weirdest people in the world? Behav Brain Sci. 2010;33:61-135.

46. Deliza $\mathrm{R}, \mathrm{Macfie} \mathrm{HJH}$. The generation of sensory expectation by external cues and its effect on sensory perception and hedonic ratings: a review. J Sens Stud. 1996;2:103-28.

47. Woods AT, Poliakoff E, Lloyd DM, Dijksterhuis GB, Thomas A. Flavor expectation: the effect of assuming homogeneity on drink perception. Chemosens Percept. 2010;3:174-81.

48. Peynaud E. The taste of wine: the art and science of wine appreciation. London: Macdonald \& Co.: 1987.

49. Anon. The search for metaphorical matchings through wine and music. 2015. http://www.1855oxford.com. Accessed 12 August 2015.

50. Bronner K, Frieler K, Bruhn H, Hirt R, Piper D. What is the sound of citrus? Research on the correspondences between the perception of sound and flavour. In: Tsougras C, Mavromatis P, Pastiadis K, editors. Proceedings of the ICMPC - ESCOM 2012 Joint Conference. Thessaloniki: School of Music Studies, Aristotle University of Thessaloniki; 2012. p. 42-8.

51. Crisinel A-S, Cosser S, King S, Jones R, Petrie J, Spence C. A bittersweet symphony: systematically modulating the taste of food by changing the sonic properties of the soundtrack playing in the background. Food Qual Pref. 2012:24:201-4.

52. Crisinel A-S, Jacquier C, Deroy O, Spence C. Composing with cross-modal correspondences: music and smells in concert. Chemosens Percept. 2013;6:45-52.

53. Knoeferle KM, Woods A, Kappler F, Spence C. That sounds sweet: using crossmodal correspondences to communicate gustatory attributes. Psychol Market. 2015:32:107-20.

54. Mesz B, Sigman M, Trevisan MA. A composition algorithm based on crossmodal taste-music correspondences. Front Hum Neurosci. 2012;6:71.

55. Wang QJ, Woods A, Spence C. "What's your taste in music?" A comparison of the effectiveness of various soundscapes in evoking specific tastes. i-Perception. in press.

56. McKenna G. Wine Vision: Wine must engage all the senses, say professors. In: Harpers. 2014. http://www.harpers.co.uk/news/wine-visionwine-must-engage-all-the-senses-say-professors/373655.article. Accessed 10 August 2015.

57. Siddle R. Wines of Argentina's Cambalache event shows way ahead for consumer wine tastings. In: Harpers. 2013. http://www.harpers.co.uk/winesof-argentinas-cambalache-event-shows-way-ahead-for-consumer-winetastings/346742.article Accessed 10 August 2015.

58. King J. Krug champagne redefines tasting notes with orchestra event. In: Luxury Daily. 2014. http://www.luxurydaily.com/krug-champagne-redefinestasting-notes-with-orchestraevent/. Accessed 6 August 2014. 
59. Velasco C, Jones R, King S, Spence C. Assessing the influence of the multisensory environment on the whisky drinking experience. Flavour. 2013;2:23.

60. Rosenthal R. Experimenter outcome-orientation and the results of the psychological experiment. Psychol Bull. 1964;61:405-12.

61. Rosenthal R. Experimenter effects in behavioral research. New York: Appleton-Centry-Crofts; 1966.

62. Rosenthal R. Covert communication in the psychological experiment. Psychol Bull. 1967;67:356-67.

63. Doyen S, Klein O, Pichon C, Cleeremans A. Behavioural priming: it's all in the mind, but whose mind? PLoS One. 2012;7:e19081.

64. Intons-Peterson MJ. Imagery paradigms: how vulnerable are they to experimenters' expectations? J Exp Psychol Hum Percept Perform. 1983:9:394-412.

65. Levitt SD, List JA. Was there really a Hawthorne effect at the Hawthorne plant? An analysis of the original illumination experiments. Am Econ J Appl Econ. 2011;3:224-38.

66. Mayo E. Hawthorne and the Western Electric Company. The social problems of an industrial civilization. London: Routledge; 1949.

67. Zdep SM, Irvine SH. A reverse Hawthorne effect in educational evaluation. J Edu Psychol. 1970;8:89-95.

68. Baral S. New app will help you pair music with your champagne. In: iDigitalTimes. 2015. http://www.idigitaltimes.com/krug-app-will-tell-youwhat-music-pair-your-champagne-456934. Accessed 9 August 2015.

69. Jones S. Krug uses music to communicate Champagne taste digitally. In: Luxury Daily. 2014. http://www.luxurydaily.com/krug-uses-music-to-exploredifferences-between-champagne-varieties. Accessed 9 August 2015.

70. North AC, Hargreaves DJ, McKendrick J. In-store music affects product choice. Nature. 1997;390:132

71. North AC, Hargreaves DJ, McKendrick J. The influence of in-store music on wine selections. J Appl Psychol. 1999;84:271-6.

72. Sester C, Deroy O, Sutan A, Galia F, Desmarchelier J-F, Valentin D, et al "Having a drink in a bar": an immersive approach to explore the effects of context on drink choice. Food Qual Pref. 2013;28:23-31.

73. Gueguen N, Jacob C, Le Guellec H, Morineau T, Lourel M. Sound level of environmental music and drinking behavior: a field experiment with beer drinkers. Alcohol Clin Exp Res. 2008:32:1-4.

74. McCarron A, Tierney KJ. The effect of auditory stimulation on the consumption of soft drinks. Appetite. 1989:13:155-9.

75. McElrea H, Standing L. Fast music causes fast drinking. Percept Mot Skills. 1992;75:362.

76. Forsyth AJM, Cloonan M. Alco-pop? The use of popular music in Glasgow pubs. Pop Music Soc. 2008;31:57-78.

77. North A, Hargreaves D. The social and applied psychology of music. Oxford: Oxford University Press; 2008

78. Spence C, Shankar MU. The influence of auditory cues on the perception of, and responses to, food and drink. J Sens Stud. 2010;25:406-30.

79. Robertson D. Why quiet restaurants are having a moment. In: The Daily Telegraph. 2015. http://www.telegraph.co.uk/foodanddrink/restaurants/ 12014962/Why-quiet-restaurants-are-having-a-moment.html Accessed 26 November 2015

80. Anon. Music 'can enhance wine taste'. In: BBC News. 2008. http://news.bbc. co.uk/go/pr/fr/-/1/hi/uk/7400109.stm. Accessed 14 April 2008.

81. Spence C, Piqueras-Fiszman B. Technology at the dining table. Flavour. 2013;2:16.

82. Spence C, Piqueras-Fiszman B. The perfect meal: the multisensory science of food and dining. Oxford: Wiley-Blackwell; 2014.

83. Bartoshuk LM. Separate worlds of taste. Psychol Today. 1980;14:48-9,51,4-6,63.

84. Spence $C$. The supertaster who researches supertasters. In: The BPS Research Digest. 2013. http://www.bps-research-digest.blogspot.co.uk/2013/ 10/day-4-of-digest-super-week-supertaster.html. Accessed 10 August 2015.

85. Prescott J. Taste matters: why we like the foods we do. London: Reaktion Books; 2012

86. Styles O. Parker and Robinson in war of words. In: Decanter. 2004. http://www. decanter.com/wine-news/parker-and-robinson-in-war-of-words-102172/. Accessed 18 August 2015

87. Sachse-Weinert M. Voce:divino in München. Synästhesie in perfektion. [Voce:divino in Munich: Pure synaesthesia]. Weinfeder J. 2014;43:34-5.

88. Knapton S. To cut down sugar just change the background music. In: The Daily Telegraph. 2014. http://www.telegraph.co.uk/news/science/sciencenews/10898123/To-cut-down-on-sugar-just-change-the-background-music htmls. Accessed 30 November 2015.
89. Spence C, Wang QJ. Wine \& music (I): On the crossmodal matching of wine \& music. Flavour. 2015:4:34

90. Beardsley MC. Aesthetics: problems in the philosophy of criticism. New York: Harcourt, Brace \& Company; 1958.

91. Tefler E. Food as art. In: Neill A, Ridley A, editors. Arguing about art: Contemporary philosophical debates. 2nd ed. London: Routledge; 2002. p. 9-27.

92. Gurney E. The power of sound. Reprint. London: Forgotten Books; 1880.

93. McNeil A. Why Hindustani musicians are good cooks: analogies between music and food in North India. Asian Music. 2008;25:69-80.

94. Stein BE, Meredith MA. The merging of the senses. Cambridge: MIT Press; 1993.

95. Holt-Hansen K. Taste and pitch. Percept Mot Skills. 1968;27:59-68.

96. Anon. Beer and music evening. 2015. http://auricle.org.nz/beer-and-musicevening-with-harringtons/. Accessed 4 August 2015.

97. Holt-Hansen K. Extraordinary experiences during cross-modal perception. Percept Mot Skills. 1976:43:1023-7.

98. von Hornbostel EM. The unity of the senses. In: Ellis WD, editor. A source book of Gestalt psychology. London: Routledge and Kegan Paul; 1927/1950. p. 210-6.

99. Rudmin F, Cappelli M. Tone-taste synesthesia: a replication. Percept Mot Skills. 1983:56:118.

100. Jack A, Roepstorff A. Trusting the subject? Volume 1. The use of introspective evidence in cognitive science. Exeter: Imprint Academic; 2003.

101. Blumenthal $H$. The big Fat Duck cookbook. London: Bloomsbury; 2008.

102. De Lange C. Feast for the senses: Cook up a master dish. In: New Scientist. 2012. http://www.newscientist.com/article/mg21628962.200-feast-for-thesenses-cook-up-a-master-dish.html. Accessed 21 December 2012

103. Pelowski M. Tears and transformation: feeling like crying as an indicator of insightful or "aesthetic" experience with art. Front Psychol. 2015;6:1-23.

104. Vessel EA, Starr GG, Rubin N. Art reaches within: aesthetic experience, the self and the default mode network. Front Neurosci. 2013:7:258.

105. Michel C, Velasco C, Gatti E, Spence C. A taste of Kandinsky: assessing the influence of the visual presentation of food on the diner's expectations and experiences. Flavour. 2014;3:7.

106. Reinoso Carvalho F, van Ee R, Rychtarikova M, Touhafi A, Steenhaut $K$, Persoone $\mathrm{D}$, et al. Does music influence the multisensory tasting experience? J Sens Stud. 2015;30:404-12.

107. Jones CA. Sensorium: embodied experience, technology, and contemporary art. Cambridge: MIT Press; 2006

108. Schwartzman M. See yourself sensing: redefining human perception. London: Black Dog Publishing; 2011.

109. Piesse CH. Piesse's art of perfumery. 5th ed. London: Piesse and Lubin; 1891.

110. Spence C. Multisensory advertising \& design. In: Flath B, Klein E, editors. Advertising and design. Interdisciplinary perspectives on a cultural field. Bielefeld: Verlag; 2014. p. 15-27.

111. Spence $C$. Sound design: how understanding the brain of the consumer can enhance auditory and multisensory product/brand development. In: Bronner K, Hirt R, Ringe C, editors. Audio Branding Congress Proceedings 2010. Baden-Baden: Nomos Verlag; 2011. p. 35-49.

112. Spence C. Sound advice. Cocktail Lovers. 2013:18-9.

113. Wang QJ, Spence C. Assessing the influence of the multisensory atmosphere on the taste of vodka. Beverages. 2015;1:204-17.

114. Anon. Experiential marketing goes multi-sensory. In: EbiquityOpinion. 2012. http://blog.ebiquity.com/2012/08/experiential-marketing-goes-multi-sensory. Accessed 10 August 2015

115. Spence C, Deroy O. How automatic are crossmodal correspondences? Conscious Cogn. 2013;22:245-60.

116. Stafford LD, Fernandes M, Agobiani E. Effects of noise and distraction on alcohol perception. Food Qual Pref. 2012;24:218-24.

117. Rosenthal R. The "file drawer problem" and tolerance for null results. Psychol Bull. 1979;86:638-41.

118. Erlebacher A, Sekuler R. Response frequency equalization: a bias model for psychophysics. Percept Psychophys. 1971;9:315-20.

119. Harrar V, Smith B, Deroy O, Spence C. Grape expectations: how the proportion of white grape in Champagne affects the ratings of experts and social drinkers in a blind tasting. Flavour. 2013;2:25

120. Anon. To make the perfect wine you need sweet music, according to Austrian winemakers. In: Daily Mail. 2011. http://www.dailymail.co.uk/news/ article-1363587/To-make-perfect-wine-need-sweet-music.html. Accessed 10 August 2015 
121. Spence C, Puccinelli NM, Grewal D, Roggeveen AL. Store atmospherics: a multisensory perspective. Psychol Market. 2014;31:472-88.

122. Spence C, Shankar MU, Blumenthal H. 'Sound bites': auditory contributions to the perception and consumption of food and drink. In: Bacci F, Melcher D, editors. Art and the senses. Oxford: Oxford University Press; 2011. p. 207-38.

123. Baker N. Johnnie Walker reveals futuristic glass. 2015. http://www. thedrinksbusiness.com/2015/04/johnnie-walker-reveals-futuristic-glass/. Accessed 7 July 2015.

124. Brown P. Ale, ale, rock and roll! Word Mag. 2012;3:28-9.

125. Gopnik A. Sweet revolution. In: The New Yorker. 2011. http://www. newyorker.com/magazine/2011/01/03/sweet-revolution. Accessed 10 August 2015.

Submit your next manuscript to BioMed Central and we will help you at every step:

- We accept pre-submission inquiries

- Our selector tool helps you to find the most relevant journal

- We provide round the clock customer support

- Convenient online submission

- Thorough peer review

- Inclusion in PubMed and all major indexing services

- Maximum visibility for your research

Submit your manuscript at www.biomedcentral.com/submit
Biomed Central 